\title{
Do LUIS CIFUENTES DELATTE, Do LUIS: CLÍNICO, CIRUJANO E INVESTIGADOR
}

\author{
Angel Escudero Barrilero
}

Servicio de Urología. Hospital Ramón y Cajal. Madrid. España.

Resumen.- El autor, discípulo del Dr. Cifuentes realiza una reflexión sobre la influencia y enseñanzas de su maestro destacando algunos aspectos que le marcaron especialmente.

Resalta su capacidad de observación de la realidad, su minuciosidad en la lectura de todas las pruebas, el análisis de toda la información obtenida y el rigor intelectual en la elaboración de sus diagnósticos.
Destaca su interés por el enfermo, sus reflexiones sobre el cáncer de vejiga, la importancia de la Estadística y la introducción y defensa de la cirugía endoscópica en España. Así mismo su defensa de la Urología como especialidad médico-quirúrgica.

Como conclusión tenemos su mejor legado: su pensamiento, sus libros y sus trabajos científicos.

Palabras clave: Luís Cifuentes Delatte. Cirujano. Investigador. Historia Urología.

Summary.- The author, disciple of Dr. Cifuentes, thinks about the influence and teaching of his professor emphasizing some features that specially marked us.

We emphasize his capacity to observe reality, his meticulous reading of all tests, his analysis of all the information obtained, and his intellectual rigor in the elaboration of the diagnosis.

His interest for the patient, his thoughts about bladder cancer or the importance of statistics, and the introduction and support of endoscopic surgery in Spain are outstanding features. It is also outstanding his defense of Urology as a medical-surgical specialty.

As a conclusion we have his best legacy: his thought, his books and scientific works.

Keywords: Dr. Luis Cifuentes Delatte. Surgeon. Investigator. History of Urology. 


\section{INTRODUCCIÓN}

Insaciable observador de la realidad, convierte esta tarea en actos cotidianos, se esfuerza en comprobar lo observado y analiza sus observaciones con absoluta objetividad y rigor intelectual. Sin ataduras ni intromisiones de ningún tipo, las aplica a la clínica siempre pensando en favorecer al paciente, en mejorarle en la medida de lo posible evitando efectos secundarios innecesarios.

Sitúense por un momento en el siglo pasado, en la década de los 50, durante la cual se recopilaban los datos y surgieron las ideas que expone el Dr. Cifuentes Delatte en su libro "Cirugía urológica endoscópica: fundamentos, indicaciones y técnicas" publicado en el año 1961.

Las grandes ideas, los grandes descubrimientos, una vez aflorados, parecen tan sencillos, estaban ahí y al alcance de todos, pero sólo a unos pocos les cabe el honor del descubrimiento.

Do Luis extraía información de Historia y Exploración Clínica, que realizaba detenida y cuidadosamente.

Los síntomas, los signos, Do Luis lo sabía, son consecuencia de las alteraciones del aparato urinario. Mientras el enfermo le refiere su historia, él visualiza lo que ocurre en su interior.

Dice "supongamos el reciente síntoma de una hematuria". El día de la consulta, él ve el sedimento: "sólo existe microhematuria residual sin células de descamación". Puede haber sido causada al desprenderse un pequeño calculito de una papila, dejando una superficie cruenta responsable del sangrado. Ésto es frecuente en la litiasis cuando el enfermo todavía no ha tenido cólico. Ahora bien, entre los hematíes objetiva un número más o menos grande de células epiteliales redondas o en raqueta, mayores que leucocitos, sueltas o agrupadas, sin que se vean en ellas grandes atipias estructurales, e incluso pequeños fragmentos de papilas tumorales. El significado es muy otro.

De él aprendí a hacer responsable de la hematuria al adenoma de próstata, sólo cuando se ha descartado una neoplasia.

Sigue vigente, aunque por muchos olvidado, la importancia que da al tacto bimanual bajo anestesia que nunca debe ser omitido. Él dice que su valor pronóstico es muy grande y yo añado que da más información en cuanto a la consistencia del tumor y movilidad y operabilidad de la masa que la que se puede extraer de un TAC. La palpación positiva de los ligamentos ínfero-laterales derivados de la fascia endopélvica por donde discurren vasos sanguíneos y linfáticos, indica extensión extravesical de la misma. La vejiga fija traduce la invasión de las vísceras adyacentes o del hueso. Cuando la base no está indurada el tumor no es infiltrante y se llegaba a decir que cuando dicha base se palpa indurada antes de la RTU y después de la misma no se toca, el tumor se puede incluir en el estadio T1. Como luego veremos, con ésto último no estaba de acuerdo.

Considera tan importante el estudio del sedimento urinario por el urólogo "que es tan absurdo no observarlo como lo sería enviar al enfermo al proctólogo pidiendo un informe sobre la palpación rectal de la próstata".

Es el inventor de las Consultas de rápida resolución, interpretaba el sedimento urinario en el laboratorio de su Consulta y la sala de endoscopias estaba disponible las 24 horas del día.

Habla de "sus" pacientes. Cúanto ha perdido el enfermo al pasar a ser un número; hoy los sustantivos enfermo y paciente han sido sustituidos por cliente, asegurado, y lo que es peor por usuario.

Pocos ahora se refieren a "sus" pacientes. Al enfermo le atiende el grupo: uno le hace la historia, otro le explora, no sé quien le hace la ecografía, luego viene otro y ve los resultados de las exploraciones que interpreta meses después de haber sido hechas, muchas de ellas ya recomendadas para evitar que te llevan al juzgado y si considera preciso realizar alguna exploración más el resultado lo verá otro; después viene otro y lo opera y serán muchos otros quienes le revisarán en el futuro.

Para su citología urinaria -porque así se puede llamar al estudio que él hace del sedimento- el microscopio óptico no le sacia y recurre al de contraste de fases. Con éste, las células de reparación del epitelio vesical, aparecen en la fase de reparación tras una cistitis y en los cálculos vesicales, siendo en mayor número y redondas, diferenciándose de las descamadas por el papiloma porque el examen periódico del sedimento asiste a la disminución progresiva del número de estas células.

Describe los histiocitos. Imposibles de objetivar con el microscopio óptico, se observan con el de contraste de fases como células irregulares, alargadas, poligonales o de forma muy diversa, de tamaño algo superior al de los leucocitos; con citoplasma finamente granular, de tono grisáceo y más oscuro que el de los polinucleares. Con frecuencia presentan fi- 
nas prolongaciones citoplasmáticas. Otras veces son alargados, de forma tuberosa, con cortos filamentos en uno de sus extremos. Deben ser conocidos para diferenciarse de las células neoplásicas y su significado es muy inespecífico

Insiste en el aspecto cuantitativo de la presencia de células, "pueden existir dudas en displasias iniciales o pequeños papilomas absolutamente benignos, en los que el examen citológico especializado no encuentra rasgos bien determinados de malignidad". Cuando estas células, que incluso pueden ser prácticamente normales, son muy abundantes se debe pensar en la papilomatosis vesical por su gran cantidad y da gran importancia a la hematuria microscópica asociada. Hay que tener presente que aún al analista más experto escapan las células bien diferenciadas típicas de la recidivas papilomatosas benignas, por lo cual la citología nunca será tan segura como una endoscopia.

El microscopio de fases le permite observar: la desproporción núcleo-citoplasma, nucleolos grandes, núcleos grandes e irregulares y la morfología monstruosa de las células, su polimorfismo. Considera los acúmulos celulares "pequeñísimos fragmentos de papiloma que se han desprendido de la masa".

Extraía signos de gran valor del examen en fresco del sedimento urinario ialguien lo ha hecho después?. Sacaba la casi total información de la inagotable que existe en la exploración radiológica: placa simple, urografía intravenosa, cistografía retrógrada y uretrografía retrógrada y miccional.

Insistía, para todos los que quisieran oírle, que los signos radiológicos muy evidentes, los que saltan a la vista, nunca pasan desapercibidos, pero, en las radiografías hay que buscar otros menos aparatosos y no por ello de menor transcendencia. Hay que estudiar las radiografías desde el ángulo superior izquierdo hasta el derecho y de arriba abajo; leerlas en toda su extensión hasta terminar por el ángulo inferior derecho. Qué diferencia con lo que muchos hacen hoy, se limitan a leer el informe del radiólogo.

Procesa toda la información extraída para llegar a aun diagnóstico, indicar el tratamiento $y$, si es quirúrgico, para plantearse la técnica a realizar en ese caso.

Recomendaba rumiar las intervenciones, incluso de la menos complicada siempre se obtiene algo que sirve para programar la siguiente $y$, por supuesto, aplicable a otras aparentemente muy distintas en todos los aspectos.

\section{SU INTERÉS POR EL ENFERMO}

Su idea sobre la indicación de las exploraciones quedó plasmada en el prólogo de nuestro libro "Exploraciones Urológicas": no emplear ni una menos de las que se juzgue convenientes ni una más de las que se crean necesarias para llegar a un perfecto diagnóstico, sobre el que se apoye el tratamiento, acaso una indicación operatoria, y se base un pronóstico bien fundamentado. Pero no caer en el riesgo de un excesivo amor a la iconografía, sobretodo, si la exploración encierra el más pequeño riesgo evitable.

Refiere la estupefacción que le produjo oír a un colega extranjero decir: "aquí hacemos sistemáticamente (y subrayaba con énfasis sistemáticamente) una arteriografía a todo enfermo de riñón que entra en el Servicio". Es posible, continúa, que lo más difícil sea no hacer nada de manera sistemática, sino selectiva. "Nosotros no fabricamos tornillos ni tubos de plástico, sino que hablamos e intentamos consolar y tratar a hombres enfermos, de complexiones, edades y caracteres muy diferentes".

Investiga para ayudar. "Sólo la inquisición de las causas, de sus diferentes formas clínicas, de las dificultades diagnósticas y del valor de los distintos métodos terapéuticos, podrá darnos armas útiles para combatirlos". Además del insospechado interés teórico, mucho bien podemos seguir haciendo en alivio del sufrimiento a quien "una cistitis crónica, rebelde y dolorosa, termina anulando para la vida de relación, su sueño se interrumpe muy a menudo y a veces se hace imposible".

\section{CÁNCER DE VEJIGA}

La descripción que hace del epitelio normal de la vejiga en su libro "Cistitis y cistopatías" (segunda edición corregida y aumentada con respecto a la primera) no tiene parangón en la literatura urológica ni en textos-trabajos histológicos ni anatomopatológicos.

En el libro "Cirugía urológica endoscópica" diferencia "las neoplasias de vellosidades largas" los llamados papilomas de las demás "formas clínicas e histiopatológicas".

Define el papiloma como "neoplasia vellosa, de vellosidades largas y finas, de color casi análogo a la mucosa normal o un poco más rosado con un fino pedículo". En los cortes histológicos presenta un epitelio de 4 - 5 hileras de células, -dispuestas entorno a un eje conjuntivo-vascular con la membrana 
basal perfectamente respetada-, que no pueden diferenciarse de las que constituyen el epitelio en reposo, e incluso conservan su polaridad, y puede encontrarse en ellos "un primer grado de desdiferenciación". En el protoplasma, la sobrecarga de grasa, que se pone de manifiesto por las coloraciones con Sudán, es tanto mayor cuanto más atípicos sean los tumores vesicales.

Su descripción da una imagen más real que la que proporciona la visión de las fotografías y añade la correlación endoscópico-anatomopatológica.

Están incluidos en el estadio 0 de la clasificación de Jewett y Marshal, improbables en el estadio A y totalmente imposibles en los estadios más avanzados.

En contra del sentimiento general de que los brotes conjuntivos vasculares "estaban recubiertos de epitelio"; expresa su pensar: los brotes conjuntivos-vasculares "siguen fielmente los movimientos del epitelio. El impulso primitivo de crecimiento anómalo reside en el epitelio. El espesor no cambia apenas, pero sí aumenta su superficie".

El papiloma simple no es más que un verdadero epitelioma en el que las papilas están muy marcadas, pero "no porque crezcan y empujen al epitelio, sino, porque este se pliega como consecuencia de un aumento local de superficie y el conjuntivo le sigue en su crecimiento". ¿ Hace falta el esquema explicativo para ver las células crecer y multiplicarse y deslizarse y plegarse y exigir al conjuntivo el sostén y nutrientes necesarios?. Las imágenes son redundancia de la descripción que él hace.

"Esta interpretación morfogénica, que me fue sugerida por la simple consideración de la forma y de la estructura de los papilomas, tiene pocos antecedentes bibliográficos", tan solo, dice: "posteriormente, he hallado una coincidencia en un precedente estudio de Masson sobre los papilomas cutáneos".

Desde el punto de vista conceptual no es superfluo que "la transformación neoplásica se inicia en la célula epitelial y no en el conjuntivo". Desecha el término fibro-epitelioma "por ser esta neoplasias de estirpe puramente epitelial y el tejido fibroso mero acompañante, como los vasos".

Distingue crecimiento en superficie (vellosidad) de crecimiento en profundidad (infiltración). Cuando el crecimiento es más acelerado, las vellosidades se van haciendo cada vez más gruesas y cortas, aumenta el número de hileras celulares, aumenta el número de mitosis y monstruosidades nucleares con manifiesta anarquía celular. El papiloma alberga en su base o en las papilas malignidad potencial que puede llegar o no a desarrollarse. En los papilomas atípicos o degenerados la microscopia muestra monstruosidades nucleares.

Hasta aquí, la membrana basal que ha sido respetada pronto no lo será más, entonces se debe hablar de carcinoma papilar. El aumento en superficie del epitelio se sustituyó por crecimiento en espesor y endoscópicamente las papilas se hacen más cortas, más gruesas, la base de implantación se ensancha, la mucosa vesical "normal" que rodea a la base están enrojecida y edematosa y al final sólo hay un crecimiento sólido, macizo, desordenado e infiltrante.

La correlación entre estructura y morfología endoscópica de los tumores la expresaba así: "el aspecto endoscópico es un trasunto, una expresión macroscópica de la estructura íntima". El urólogo que conoce bien esta correlación sabe que el aspecto endoscópico tiene valor diagnóstico y pronóstico. Pocos trabajos se han publicado después insistiendo en dicha correlación.

\section{¿Cuál es el límite, hasta dónde puede llegar la cirugía endoscópica en los tumores vesicales?}

La resección endoscópica de un papiloma vesical no puede discutirse. Con la RTU y las revisiones periódicas cambia de forma radical "el concepto que el urólogo tiene de estas neoplasias, altera por completo la base práctica y teórica de su tratamiento". Permite seguir más de cerca y conocer más fielmente su evolución clínica e histopatológica y "trastornar también esta evolución, ya que el tratamiento endoscópico se puede reiterar". La parte de malignidad potencial de los papilomas es un hecho real "pero que el tratamiento y la vigilancia sistemática del enfermo impide que se realiza al cortar su evolución cuando se halla en sus comienzos".

Insistió sobre el efecto citolítico del agua como prevención de las recidivas por implante de las células sueltas durante la resección.

Los carcinomas sólidos, infiltrantes, macizos, sin ninguna tendencia a la formación vellosa, carecen totalmente de indicación de RTU y toda maniobra que se realice en ellos será absolutamente inútil o puede ser perjudicial excepto si son sorprendidos de pequeño tamaño.

Tacha la recomendación de Thompson de resecar hasta la grasa de "consejo tan atrevido como 
heterodoxo". Y tampoco está muy de acuerdo con la primera parte del pensamiento de lglesias, que cree que la resección amplia de la pared vesical no trae posteriores complicaciones, mientras que a las perforaciones pequeñas las considera peligrosas.

Piensa que la RTU es totalmente inútil para los carcinomas francamente malignos. Posteriormente se expresara así: sin compartir esta actitud extremista "me parece ya de mayor interés que cuando leí sus trabajos por primera vez".

No suele verse transformación papilar benigna en la uretra membranosa ni en la anterior ya que el epitelio de transición termina en el límite distal de la uretra prostática. "La gran frecuencia de casos con extensión del proceso neoplásico al epitelio de la uretra prostática, localización que suele pasar desapercibida en las operaciones a vejiga abierta"; es perfectamente identificada-al igual que las del cuello vesical o de las proximidades de éste- cuando la tumoración se observa con el uretrocistoscopio o el resector de óptica foroblique y de su agresividad se adquiere una idea más cercana a la realidad con el resector que cuando se explora con el cistoscopio, con éste parecen más o menos macizas cuando en realidad son tumoraciones vellosas.

Apunta la posibilidad de que los buenos resultados descritos en casos de "carcinomas vesicales" se pueden deber a que autores, fundamentalmente americanos, llaman carcinoma grado I a lo que en Europa se llama papiloma benigno. "Naturalmente la confusión es sólo de palabra" y alerta "pero, tiene el riesgo de llegar a ser de conceptos".

En enfermos ancianos prefiere la resección endoscópica paliativa con fines hemostáticos que puede librarles durante mucho tiempo de la hematuria. "En estos casos valora el temor a originar mayores molestias al enfermos mediante un tratamiento radioterápico que suele causarle, si es intenso, una rebelde cistitis ulcerosa de irradiación a veces sin que desaparezca la tumoración".

Recomienda la inyección de oro en tumores cuya infiltración no pase de la capa más superficial de la muscular, pero "en tumoraciones de mayor tamaño o de localización nada favorable, se puede aconsejar un intento de cirugía conservadora a vejiga abierta, infiltrando después la base con oro coloidal o implantando agujas de oro radioactivo, semillas de Radón, alambres de Tantalo, y si no fuera posible decidirse por una cistectomía radical.

Sustituye la técnica de implantar el oro radioactivo mediante la punción suprapúbica por su método. Inyecta el 198Au mediante una aguja cistoscópica e infiltra todo el lecho de la tumoración previamente resecada ampliamente, limitando la radiación a la porción afectada de la vejiga dejando libres las estructuras normales. Hay neoplasias vesicales francamente degeneradas y atípicas que infiltran poco la pared, en estos casos, se puede extirpar todo el tejido neoplásico, con la resección se llega hasta la misma capa muscular y es posible resecar "con sumo cuidado" la porción más superficial de la misma si se considera infiltrada, "pero, nunca tendremos la completa seguridad de que hayan desaparecido los últimos acúmulos celulares o cordones neoplásicos infiltrantes". Estos restos "pueden ser destruidos mediante el oro coloidal inyectado intramuralmente en toda la base de implantación".

Carcinoma "in situ". El epitelio normal de la vejiga se ha transformado y sustituido por otro en el que las células tienen carácter neoplásico. "Pequeños focos de células atípicas con núcleos patológicos que no supone un aumento de superficie del epitelio ni apenas un aumento de su espesor, sino, fundamentalmente una alteración del tipo de células; es una degeneración del epitelio que en su comienzo respeta la membrana basal aunque por muy poco tiempo".

Los considera como una fase, como un estadio, para él muchos carcinomas macizos se inician en forma de carcinoma "in situ".

Él, estudiando el sedimento, observa que las células ya son muy abundantes en los primeros estadios, pero, pueden no tener caracteres atípicos y el examen citológico habitual dará informes poco expresivos negativos de neoformación maligna. Sin embargo, en un síndrome de cistitis rebelde, con pequeñas hematurias, a veces no muy acentuado pero persistente, sin piuria ni bacteriuria, con cistoscopia negativa de neoformación; "la presencia de gran cantidad de células redondas, de tamaño superior al de los leucocitos hace pensar en un carcinoma intraepitelial". Al disminuir la adhesión celular existe mayor tendencia a la exfoliación, lo cual hace que sea fácil de diagnosticar con una simple citología, aún en los casos en que no muestra alteraciones endoscópicas.

En nuestra experiencia, dice, los hallazgos cistoscópicos, a veces bastante característicos, ayudan a sospechar el diagnóstico que será comprobado por el examen citológico $y$, fundamentalmente por el resultado de la biopsia.

Lo describe como áreas enrojecidas con granulaciones diminutas, casi siempre amarillentas $y$, a veces, del color de la mucosa que se observan mejor en visión endoscópica próxima; colocar la óptica 
muy cerca de la mucosa permite una ampliación de la imagen, como si la lesión fuera contemplada con una lupa.

Otras veces son zonas de proliferación, irregularidades y espesamiento en la mucosa, sin morfología típica de neoplasia y con escasa elevación por encima del nivel del epitelio normal.

En ocasiones, pequeños quistes irregulares, amarillentos, por lo común sólidos y de aspecto endoscópico muy diferente a los que se observan en la cistopatía quística, que pueden corresponder a nidos de von Brunn quísticos y con degeneración neoplasica.

También se traduce por áreas hiperémicas en nada diferentes a las que pueden observarse en una cistitis intersticial.

Puede ser hallado en zonas de mucosa aparentemente normales, y como no siempre permanece sin infiltrar a través de la membrana basal, constituye un riesgo evidente, ya que puede pasar desaparecibido a la inspección durante una intervención a vejiga abierta (cistectomía parcial u operación conservadora a vejiga abierta) e incluso a la exploración endoscópica. La mucosa que rodea a un cáncer florido debe ser cuidadosamente explorada por cistoscopia, sobretodo cuando se va a conservar la vejiga, porque es en dicha zona donde con más frecuencia existe carcinoma "in situ".

Anatomía patológica. En el comienzo de la transformación neoplásica puede hablarse de displasia en vez de carcinoma "in situ". Es indudable que las características citológicas de malignidad no están perfectamente definidas.

Las células empiezan a perder su polaridad progresivamente, haciéndose oblicuas o pierden el paralelismo con las normales más próximas. El núcleo adquiere tamaños diferentes, algunos de gran tamaño, otras de contorno irregular, a veces dentado, hipercromaticos con distribución excéntrica de la cromatina densificada, e inversión de la relación núcleo-citoplasmática. Aparecen mitosis, generalmente bipolares, sólo excepcionalmente multipolares y rara vez se ven más de dos por campo microscópico de gran aumento.

Con cierta constancia existen vacuolas en el citoplasma que llegan a rechazar el núcleo, que adopta forma de semiluna. Las vacuolas no contienen mucopolisacáridos, más probablemente contienen lípidos, los cuales no pueden ser demostrados en el examen de una biopsia incluida en parafina, la cual disuelve la grasa.
En el área de transformación hay una separación entre el límite de la capa "más reciente" y el epitelio mas inmediato (superficial) normal, viéndose en ocasiones islotes aislados displásicos con desprendimiento de células superficiales maduras. Este fenómeno puede ser debido a alteraciones de la membrana celular, que hacen que la célula tumoral pierda la adhesividad que caracteriza a las células normales.

De los nidos de von Brunn piensa que si el carcinoma "in situ" puede invadirlos, hay casos en los cuales son el primer asiento de la transformación neoplásica. Aunque su constancia e intensidad hace muy difícil eludir la idea de que no sean fenómenos relacionados, hasta ahora no son más que conjeturas. En la segunda edición de su libro "Cistitis y cistopatías" se expresaba así: "todo proceso que altera la estructura normal del urotelio, incrementa la actividad mitótica y la formación de nidos epiteliales aunque en sentido reparador, alcanzado nuevamente su relativo reposo cuando la reparación de la mucosa ha llegado a su término".

Considera insuficientes ambas, la clasificación de Franksson y de la Broders. Y cree fundamental la relación del epitelio con la membrana basal (Franksson) y mejor no dar grados de Broders, sino $\%$ de atipias.

No está de acuerdo con algunos aspectos de la clasificación TNM. Si bien funde la profundidad de invasión con el grado de diferenciación celular, piensa que el estado $B 1$ no puede incluirse para el análisis estadístico junto con el $\mathrm{O}$ y el $\mathrm{A}$, como si de superficial se tratase, sólo puede "mirarse como superficial cuando se compara con el B2 o el C". No es posible reconocer la extensión de la invasión de la muscular sólo con la palpación bimanual bajo anestesia, esta información es incierta, a menos que se haya hecho al paciente una cistectomía.

De este modo, la TNM acentúa drásticamente dicha separación al identificar "los T2 con los B1 y los T3 con los B2 y C". From the dilemma "Two B's or not Two B's. For us, there is no question: not two B's."

Basado en su experiencia, con 1.744 casos tratados, propone identificar $\mathrm{T} 2$ con $\mathrm{B}$ y $\mathrm{T} 3$ con $\mathrm{C}$, y considerar $B 1=T 2 a$ y $B 2=T 2 b$ como estadios anatomopatológicos definidos por el estudio de la pieza de cistectomía parcial o total.

Con sólo ésto, cuántos resultados sobre el efecto de medidas neoadyuvantes se hubiera tenido que dejar de publicar. Partiendo de la base de que es imposible definir correctamente el estadio clínico (T) del cual se resta, el bien definido, estadio anatomo- 
patológico (P), la diferencia estadio clínico-estadio anatomopatológico no tiene sentido para valorar la eficacia de una técnica neoadyuvante: ya sea radioterapia ya sea quimioterapia.

Teniendo en cuenta el material y método -fueron revisados retrospectivamente 800 casos tratados entre 1950 y 1964 y el resto hasta abril de 1978 corresponden a un estudio prospectivo- el extraordinariamente largo seguimiento, el gran número de casos que analiza (1.744) y que ningún enfermo visto, tratado o no tratado, es excluido del análisis, lo cual afecta a casos terminales y los tratados en otras clínicas, pero que fueron manejados por ellos, la supervivencia total directa: $61 \% ; 52,2 \% ; 37,8 \%$ y $28,8 \%$ a los $3,5,10$ y 15 años respectivamente se puede considerar muy buena. $Y$ como muestra su tabla 6 mejor que la referida en muchos trabajos por aquella época publicados con series más cortas y supervivencia a 3 y 5 años exclusivamente.

\section{ESTADÍSTICA}

Amante de la estadística, de la buena, cuando se propone estudiar un tema, lo exprime hasta la saciedad. Por poner un ejemplo, en 1964 comienza la revisión de las "neoformaciones vesicales" y a primeros de 1968 revisa 1.000 casos utilizando "un sistema de codificación que pudiera ser adaptado a un ordenador", el trabajo se publica en el Journal d'Urologie 77; 1-16; 1975. Encuentra que predomina la incidencia en el hombre muy significativamente sobre la mujer: 7,69/1.

Persistiendo en la idea, entre 1967 y 1974 asiste a 524 casos nuevos y en éstos la proporción es aún mayor: $486 / 38$ o lo que es lo mismo 12,79/1. No contento con esta confirmación, reúne entre sus colaboradores 17.416 casos: "me interesaba saber cual era la situación real, con mayor valor estadístico, en una serie importante de casos vistos en toda España". En el trabajo, la lista de participantes ocupa 18 líneas, un tercio de la página de la revista. Refiere que la proporción hombre-mujer es $7,11 / 1$ y que dicha proporción es en España muy superior a la descrita en el resto de Europa: Wallance, 4, 11/1; Miller 3,07/1; Cox 2,51/1 y también que en España varía la incidencia entre diversas regiones: norte $5,2 / 1$; sudeste $11 / 1$; islas Canarias $14,1 / 1$.

Y sugiere: "Tenemos la impresión de que la evolución hacia la malignidad es más rápida en el sexo femenino".

Ahora bien, conoce las limitaciones de los porcentajes y de las posibilidades en la práctica dia- ria. La evolución de cada caso concreto de papiloma es imprevisible "podemos dar al enfermo una impresión general, de tipo estadístico, sobre la evolución de la enfermedad, pero no podemos predecir cual será la suya propia, que es justamente lo único que le interesa". Y estoy seguro que no podría imaginarse el juego de números que vendría después. También sabía reírse de ella. En una de las muchas conversaciones en su casa con las que me distinguió, daba gloria estar y conversar con él; ante mi afán por demostrarle lo bien que le encontraba física y psíquicamente, con esa amable gracia y donaire de que muchas veces hacía gala, me contestó: "Escudero no diga tonterías, yo estadísticamente muerto".

\section{CIRUGIAA ENDOSCÓPICA}

Es especialista en adivinar la escondida trascendencia de los temas, que después analiza, trabaja, adquiere experiencia y cargado de razón expone con brillante sencillez. Sus trabajos siempre empiezan por los principios fundamentales y como para exponer su experiencia, sus hallazgos y su pensamiento, el espacio de la revista le queda corto tiene que recurrir al libro.

Siempre me recomendaba que no limitara mi lectura a revistas urológicas, leer sobre otras especialidades proporciona amplitud de miras e ideas para la investigación.

Nos enseñó a identificar los límites de una resección bien hecha ¿ Cuánto nos hubiera costado aprenderlo solos?. Nos enseñó a tratar elegante y eficazmente la esclerosis de cuello vesical y a resecar los adenomas pequeños $\dot{2}$ Sabe ahora alguien lo difícil que resultaba resolver ambos procesos por vía abierta? Lo que sí creo que está al alcance de todos es comprender el beneficio que aporta la técnica al paciente con cáncer superficial de vejiga.

Libra de la sonda o de la talla al enfermo en retención por cáncer de próstata. "Es raro que la vaina del 28 ó 29 no pueda entrar y casi siempre deja pasar la del calibre 26. Cuando el resectoscopio está introducido en la vejiga se nota la dureza y resistencia del cuello vesical porque, el aparato, no puede moverse hacia dentro y fuera, ni vascularse apenas. La mayoría de las veces no es necesario hacer resecciones demasiado amplias porque "no hay estenosis de la uretra prostática".

Fundamentadas, marca las diferencias con la técnica necesaria para tratar el adenoma. La resección de una pequeña cantidad de tejido en el labio posterior del cuello es más eficaz que en el 
adenoma. La masa carcinomatosa "está más fija y es más rígida que la adenomatosa". "Con una cantidad relativamente pequeña de tejido extirpado puede labrarse una más amplia uretra posterior, asegurando un buen efecto paliativo, único fin buscado con esta intervención"; puesto que, a diferencia de lo que ocurre con el adenoma, los lóbulos laterales no caen hacia la línea media, aumentando la obstrucción, al resecar "primeramente" el labio posterior del cuello ocupado por un lóbulo medio o un lóbulo comisural.

$Y$, como siempre, insiste en que también en el adenocarcinoma de próstata hay que adaptar la técnica a las necesidades de cada caso.

"Pocas veces la retención es consecuencia de que la neoplasia comprima o produzca obstrucción mecánica de la uretra prostática". "Es sorprendente encontrarla siempre permeable y aparentemente libre a pesar de haberse comprobado, por tacto, la dureza y gran extensión del tumor". Los tumores no crecen hacia la luz uretral, sino hacia fuera. La retención se produce por "infiltración y rigidez" del cuello vesical y el esfínter liso pierde totalmente sus movimientos. Sobre esta base emplea la cirugía endoscópica. "Si la uretra aparece corta, no demasiado alterada e incluso amplia, aunque el labio posterior es más grueso que en la disectasia", "basta resecar el labio posterior del cuello, pues los efectos funcionales de esta intervención suelen ser magníficos".

Cuando se trata de un adenoma infiltrado por adenocarcinoma, no es suficiente con resecar el cuello, "habrá que realizar también una amplia re- sección de los lóbulos laterales hasta que quede, por lo menos, una uretra prostática ampliamente liberada, un verdadero hueco prostático".

En otros adenocarcinomas no se identifican bien los límites. La tendencia infiltrativa borra las referencias -bien visibles en el adenoma-. La resección distal del carcinoma puede ser extraordinariamente difícil porque enmascara el veru y puede que infiltre el esfínter externo. Una dificultad adicional "es el edema de la base vesical, sobretodo en la zona del trígono que oculta los orificios ureterales". Recomienda inyectar carmín de Índigo para localizarlos y evitar su lesión.

El aspecto endoscópico del carcinoma reseccionado difiere del de el adenoma y es muy característico: de color más bien amarillento grisáceo, la superficie de corte es finamente granulada y sangra poco.

De su posición personal ante la cirugía endoscópica dice: "está limpia de todo prejuicio personal o de escuela, no he creado el método ni he diseñado nuevos instrumentos".

Cuánta modestia destilan estas palabras. (Figuras 1 y 2). Ni más ni menos, él introdujo y defendió la cirugía endoscópica en España, qué pocos se acuerdan de eso; en la época en que yo estuve con él, la de la lámpara incandescente y cableado eléctrico y asas que se rompían con facilidad, decía que la cirugía endoscópica era como trabajar en una noche de tormenta, había que aprovechar la luz de los relámpagos para realizar la tarea.

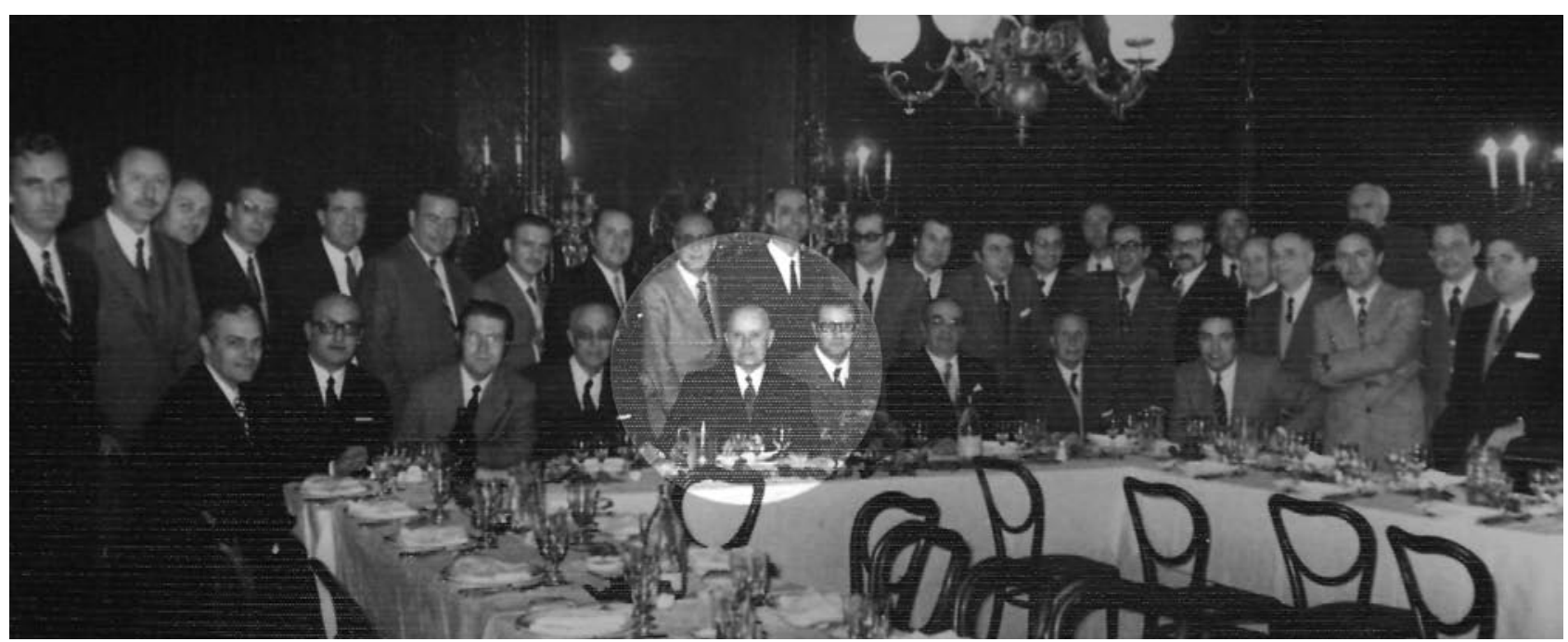

FIGURA 1. D. Luis, en una celebración con sus colaboradores (1966). 


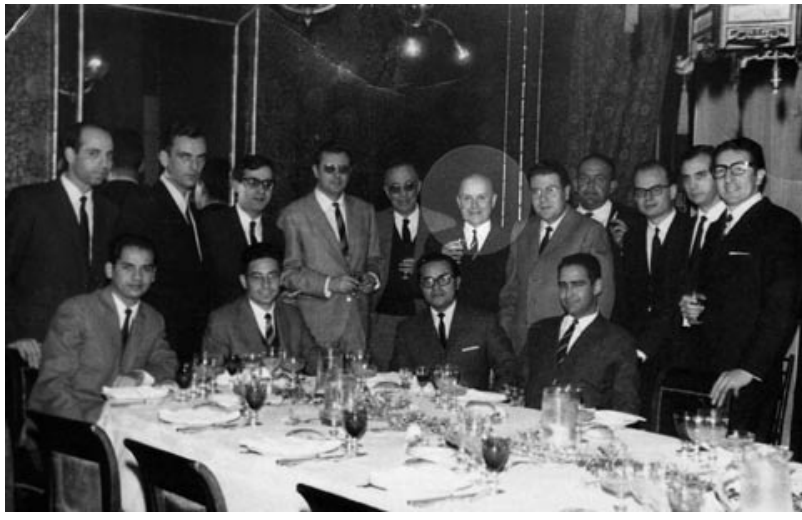

FIGURA 2. D. Luis, en la despedida del Dr. Núñez, uno de los muchos extranjeros que acudían a su Servicio para hacer la especialidad.

Su práctica, por aquellos años, era un acto de orgullo bien entendido -la tenacidad contra la adversidad- y eso que su recomendación más habitual era que con la cirugía endoscópica no hay que tener orgullo, cuando no se puede continuar se transforma en abierta. Fue quien superó las "ingratas dificultades", resolviendo problemas y transmitiendo soluciones, y quien nos enseñó a muchos, evitándonos sufrir los percances que él superó.

Se necesitaba mucho tesón, confianza en lo que se estaba haciendo y ansia de beneficiar al paciente para no desmayar como ocurrió a otros muchos.

Cuando explicaba cómo había hecho una operación endoscópica, al tiempo que hablaba, y qué bien lo hacía entonces, cuando estaba tranquilo y a gusto, ponía la mano doblando los dedos de tal forma que las falanges segunda y tercera formaban un ángulo de $90^{\circ}$ con la primera, moviendo la mano como si del asa se tratase y estuviera dentro de la vejiga, mirando hacia la zona donde estaba situado el cáncer que estaba resecando y haciéndonos imaginar a quienes le oíamos la morfología del tumor y si se me apura un poco, hasta su histología.

\section{LA ESPECIALIDAD DE UROLOGÍA}

Defensor de la Urología como especialidad, con la introducción y enseñanza de la resección endoscópica, afianza la diferencia que le da entidad.

En la Urología española, en el tratamiento de los procesos estudiados en el libro "Cirugía urológica endoscópica" y especialmente en el cáncer de vejiga hay un antes y un después, antes de $D^{\circ}$ Luis $y$ después de $D^{\circ}$ Luis. Nadie antes había conseguido favorecer tanto al enfermo.

La Urología, dice es una especialidad médico-quirúrgica. Nuestra especialidad brotó del esfuerzo de Cirujanos que acentuaron su interés por el estudio de uno de los capítulos de la Cirugía General, aquel que describía las afecciones del aparato urinario, pero su segregación definitiva fue resultado directo del perfeccionamiento del cistoscopio. Con su cirugía endoscópia, en España, acentúa la especificidad de la Urología como especialidad.

Defiende la cirugía endoscópica para el urólogo: "No estoy de acuerdo en que haga falta concebir la cirugía endoscópica, como querían otros, como una especialidad dentro de otra especialidad". Y se propone su enseñanza "son pocas las clínicas en donde este procedimiento quirúrgico puede ser aprendido y la enseñanza práctica presenta problemas muy complejos y dificultades adicionales; hay muchos trabajos dispersos y pocos libros sistemáti$\cos ^{\prime \prime}$. La técnica que expuso el 1961, es casi igual que la que se practica hoy día. Pocos retoques se han hecho en ella, y poco se puede añadir y menos rectificar. Sólo la calidad de los elementos que constituyen el resector ha mejorado y contribuido a facilitar extraordinariamente el acto quirúrgico con relación a entonces.

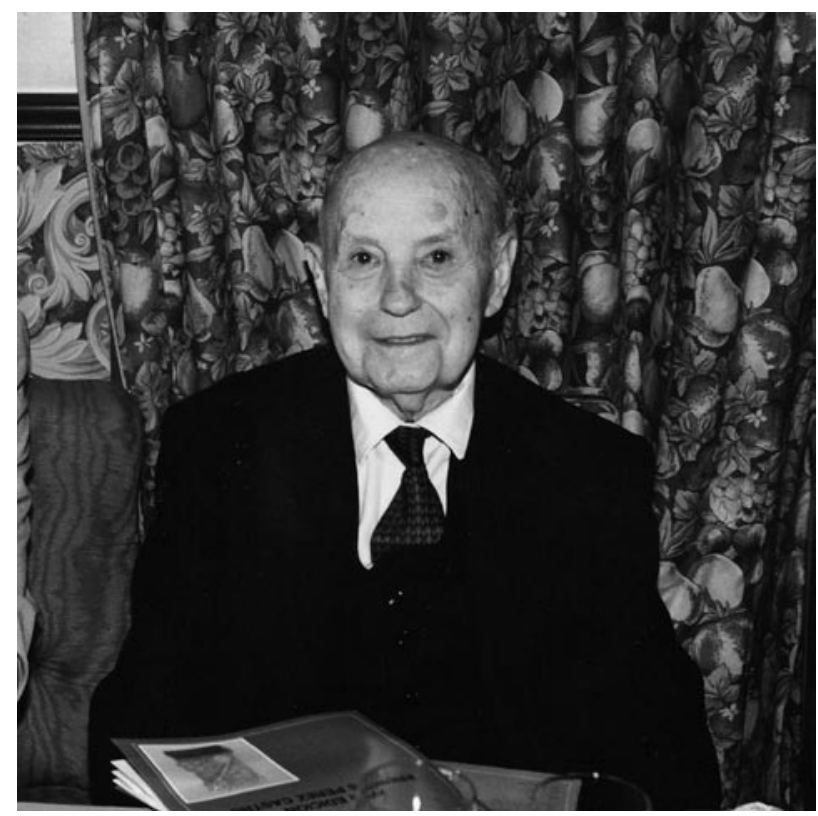

FIGURA 3. La última vez que vi su mirada inteligente que tanto me atraía inseparable de la sonrisa que iluminaba su cara.

Entrega de Premios Pérez Castro, XV Edición. 
Do Luis sigue entre nosotros, nos ha dejado su legado: su pensamiento, sus libros y sus trabajos científicos. La mejor forma de agradecer lo que le debemos es honrarle con su lectura, ejercer sus enseñanzas y mantener viva SU LETANÍA.

Su objetivo: el bien del enfermo.

Realiza una verdadera citología urinaria observando el sedimento en fresco con el microscopio de contraste de fases.

Recomienda evitar exploraciones y aplicar terapéuticas no exentas de riesgo, a menos que el beneficio para el enfermo supere los perjuicios.

La adaptación de la exploraciones a cada enfermo concreto la indicará ese juicio sereno que intenta definir lo mejor para el paciente, esa decisión es difícil y forma parte de lo mejor que hay en nuestra profesión "ese yugo de ciencia y respeto humano, ese impalpable soplo afectivo que nunca se apagará en la Medicina por muy técnica que ésta sea".

Dice en la justificación de su libro "El laboratorio del urólogo": El éxito de la cirugía se basará siempre en una técnica depurada unida a un correcto diagnóstico, logrado éste lo más rápidamente posible. El examen del sedimento permite al urólogo "adelantar horas e incluso fechas para el diagnóstico, y con las menores molestias para sus pacientes".

Basándose en que si bien "no todos los cánceres vesicales han debido comenzar como papilomas, muchos tumores malignos han tenido, sin duda, una larga fase papilomatosa de fácil curabilidad".

Está tan convencido de la necesidad de las revisiones periódicas después de haber operado un cáncer de vejiga "que si el enfermo no acude en la fecha recomendada, le escribe una carta personal y si falla se pone en contacto con su médico e incluso pide a la policía que entre en contacto con él", sistemática que también utiliza cuando revisa historias para publicar un trabajo antes de dar como perdido $a$ un enfermo.

Me maravillaba la certeza de sus indicaciones y que extraía del estudio completo del enfermo el máximo de datos útiles para operar, lo que hacía de él un buen cirujano. Sabía de antemano los problemas que le podían surgir en el campo operatorio del caso con el que se enfrentaba en ese momento y sabía, también de antemano, la solución más apropiada que debía dar. No era un mero hacedor de una técnica quirúrgica, la cirugía persigue eliminar lo patológico y restablecer la fisiología lo más cercano posible a lo normal en lo que dejamos.
Aplicar tratamientos individualizados con la finalidad de mejorar la calidad de vida. "La técnica, no es un fin en si misma, sino un medio merced al cual podemos ser útiles a nuestros enfermos". $Y$ es esencial que se aplique "sobre una justa indicación operatoria y ésta no puede ser formulada sin un sólido fundamento clínico, sin una perfecta exploración y sin una idea clara del proceso patológico que el enfermo padece. Cuántas veces se olvida esto y se hacen determinadas técnicas quirúrgicas con el solo afán de hacer número.

Honesto a carta cabal, debía de servir de ejemplo a esta generación de urólogos y a las venideras. Defiende la mayor variedad de técnicas para elegir en cada caso la que se crea más beneficiosa para el enfermo, dado su concreta afección y sus condiciones personales.

Las técnicas deben atraernos por su eficacia, única manera de perseverar en ellas y no simplemente por su novedad. En su sentir, quienes sólo dominan la cirugía abierta o sólo la endoscópica ya no tienen criterio libre ni independiente para formular su indicación de tratamiento, lo cual requiere mucho sentido común.

Recomienda enviar al patólogo como mínimo dos muestras bien diferenciadas, una con el total de tejido resecado y otra procedente de la base de implantación y "si es posible, profundizar en la muscular de esta zona". Y además, "los urólogos, dice, deben tener una experiencia personal en la histopatología, deben examinar ellos mismos las preparaciones de cada caso proporcionadas por el patólogo como el mejor complemento de un informe".

Defensor de la verdad a ultranza se expresaba con moderación y mesura. Yo creo que no decía, que no escribía, nada que no pensaba y sus ideas las había analizado concienzudamente.

En el prólogo de la segunda edición de "Cistitis y cistopatías" se expresaba así: "Y más en uno oficialmente jubilado, en todo esfuerzo late el humano deseo de sobrevivir y dar fe de vida, pero también el menos egoísta de contribuir al mejor conocimiento del tema, de ofrecer una visión integradora del estado de la investigación sobre problemas reales clínicos y de incitar a nuevos esfuerzos para su mejor estudio".

Si Aristóteles elogiaba la vida contemplativa dedicada a la búsqueda de la verdad, y sin querer polemizar con Aristóteles, yo creo que lo suyo ha sido más beneficioso, consagrar la vida activamente 
a la búsqueda de la verdad y aportar sus hallazgos para el bien del enfermo.

Sus trabajos son muy completos. Consciente de sus lógicas limitaciones, recaba la colaboración de bacteriólogos, virólogos, patólogos, espectrocopistas, microscopistas, físicos, etc... con quienes departe casi con la misma altura de conocimientos.

Resalta conversar con todos lo que intervienen en el proceso clínico: radiólogos, anatomopatólogos, otros especialistas, radioterapeutas, oncólogos, etc... y estudiar sus especialidades para sacar provecho de estas conversaciones. Cuánta información se deja de adquirir con la práctica habitual hoy día; la hoja de consulta se lanza un escrito y se recibe otro, y el que lo lanza no sabe interpretar y muchas veces, ni incluso leer lo que ha recibido.

Al rememorar los recuerdos, releer sus trabajos y escribir estas líneas, caigo en la cuenta de que muchas de las ideas que consideraba exclusivamente mías, me fueron inculcadas por él de forma insensible y, quizás, por esa manera de hacer que tenía, forjaron una huella indeleble en mi celebro.

Cada día que pasaba a su lado, sin esfuerzo por mi parte, aprendía algo, matizado, argumentado y útil para mí y para el enfermo.
Ha sido definido por el $\mathrm{Dr}$ Insausti como "entusiasta batallador, investigador nato, clínico profundo, amante de las bellas artes, ameno conversador admirable por la elegancia y caballerosidad de hidalgo castellano en su humano comportarse". Yo quiero añadir, curioso insaciable, observador profundo de la realidad diaria, incansable trabajador $y$, algo que de muy pocos se puede decir, poseía dos cualidades fundidas en una: trabajo inteligente.

Es una pena que no haya tenido más tiempo para buscar y leer con deleite más de sus trabajos. Sería necesario que todo el que se inicie en la resección transuretral lea antes la técnica descrita por Do Luis, puesto que, toda sus recomendaciones siguen vigentes y es posible que sus descripciones en este campo puedan ser ampliadas, pero poco se pueden mejorar. Sus libros agotados, sus trabajos muy dispersos, es preciso reeditar sus libros y recapitular todas sus publicaciones para que los jóvenes urólogos puedan aprender-disfrutando- como se debe hacer un trabajo científico, como exponer los hallazgos y como cargarse de razón, de argumentos veraces para llegar a unas conclusiones.

Si se compara el conocimiento con alas que elevan al cielo, Do Luis estará muy alto; entre las estrellas. Descanse en paz. 